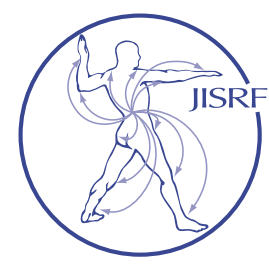

\title{
Techniques of Insertion and Early Clinical Impressions with a Short Curved Tissue Sparing Implant for Total Hip Arthroplasty (The French Experience)
}

Venet $G^{1}$, Tesson $A^{1}$, Le Cour Grandmaison $F^{1}$, Fraquet $N^{1}$, Brazil $D^{2}$, McTighe $T^{3}$

\section{Abstract}

Background: Total hip arthroplasty (THA) is one of the most effective orthopedic procedures, providing consistently high success rates across all population segments as measured by pain relief, improved function, and patient satisfaction. However clinical outcomes have been less favorable in young active patients, that lead to the re-development of metal on metal hip resurfacing (HR), with the most successful being the Birmingham Hip Replacement (BHR) introduced in 1997. Evolving complications due to increased metal ion debris has lead to a great reduction of use for all metal on metal (MOM) HR designs, leading many surgeons and patients to look for an alternative surgical selection. This search has focused on the development and use of short stems for THA. One such style of short stems is curved neck preserving designs. This paper will review our French experience with one of those designs.

Materials and Methods: This is a retrospective review of four surgeons series of a short curved tissue sparing cementless femoral implant (TSI ${ }^{\mathrm{TM}}$ Hip Stem, Signature Orthopaedics) for THA. The femoral component was used with two different cementless acetabular styles (Mathys RM Pressfit, and Zimmer Biomet Allofit ${ }^{\circledR}$ ). Results on the cups will not be revived in this paper. $150 \mathrm{TSI}^{\mathrm{TM}}$ Stems by four surgeons at the same institution utilizing the posterior surgical approach since September 2016. 40\% women, average age 66 years with extremes of 27 to 78 years. 10 cases of dysplastic hips, 6 cases of aseptic osteonecrosis, 1 fracture, 1 rheumatoid coxitis, and the rest primary coxathosis, with 7 patients operated on both hips at the same time. $23.3 \%$ have been Dorr type A canal shape.

Results: There has been no aseptic loosing, three femoral components have been explanted due to postoperative infection. There was one intra-operative femoral distal fracture in a Dorr type A bone profile during stem insertion. One posterior dislocation; there has been two patients with thigh pain with pathological bone scan, and one with low back pain and no leg length discrepancies greater than plus or minus $5 \mathrm{~mm}$.

Conclusion: This short curved tissue sparing implant has demonstrated excellent initial short-term results, with excellent implant stability, excellent medial calcar bone remodeling with one dislocated stem, two thigh pain and one patient with low back pain. One distal intra-operative fracture in a Dorr type A bone. This has now been addressed with the use of distal sizing gauges and the use of flexible reamers to open the distal canal prior to stem insertion. Removal of the infected stems demonstrated implant stability

Keywords: Tissue Sparing Implant; short curved neck preserving stem; total hip arthroplasty; bone remodeling Level of Evidence: AAOS Therapeutic Level II 
with early bone attachment in the proximal porous surface. The high neck resection allows for ease of revision and conversion implanting a new primary conventional length cementless stem design.

There is a short but definitive learning curve in fitting the implant to the femoral neck versus the standard metaphyseal and diaphyseal conventional style stems.

\section{Background}

Total hip arthroplasty (THA) is one of the most effective orthopedic procedures, providing consistently high success rates across all population segments as measured by pain relief, improved function, and patient satisfaction. [1] However, clinical outcomes have been less favorable in young active patients, $[\underline{2}, \underline{3}]$ which lead to the re-development of metal on metal hip resurfacing (HR), with the most successful being the Birmingham Hip Replacement (BHR) introduced in 1997. [4] Evolving complications due to increased metal ion debris has lead to a great reduction of use for all metal on metal (MOM) HR designs, leaving many surgeons and patients to look for an alternative surgical selection. $[\underline{5}, \underline{6}, \underline{7}]$

In the past ten years short stems and in particularly neck preserving stem designs have received a significant level of interest at continuing medical education (CME) meetings as a result of the decline of HR. $[\underline{8}, \underline{9}, \underline{10}]$

\section{Material and Methods}

This is a retrospective review of four surgeons series of a short curved tissue sparing cementless femoral implant (TSI $^{\text {TM }}$ Hip Stem, Signature Orthopaedics) for THA. The femoral component was used with two different cementless acetabular styles (Mathys RM Pressfit, and Zimmer Biomet Allofit $\left.{ }^{\circledR}\right)$. Results on the cups will not be revived in this paper.

$150 \mathrm{TSI}^{\mathrm{TM}}$ Stems by four surgeons at the same institution utilizing the posterior surgical approach since September $2016.40 \%$ women, average age 66 years with extremes of 27 to 78 years. 10 cases of dysplastic hips, 6 cases of aseptic osteonecrosis, 1 fracture, 1 rheumatoid coxitis, and the rest primary coxathosis, with 7 patients operated on both hips at the same time. $23.3 \%$ have been Dorr type A canal shape. Figure 1.

The TSI ${ }^{\mathrm{TM}}$ stem (Tissue Sparing Implant) is a short, anatomically curved stem designed to retain most of the patient's femoral neck. The implant sits in the patient's femoral neck, and curves anatomically down into the patient's
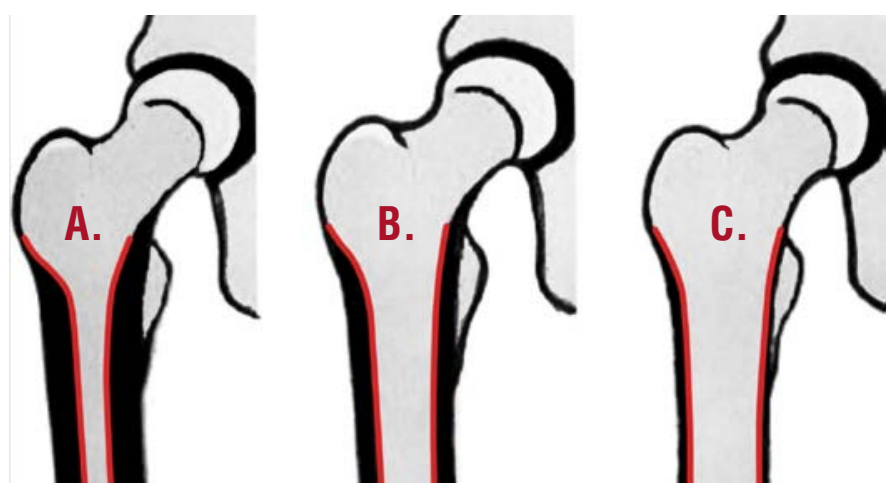

Figure 1. Illustration Dorr bone classification. Type A, narrow canal, $B$ normal canal, and $C$ wide canal.

proximal femoral canal, to maintain anatomical compressive loading of the retained bone. The stem is manufactured from Ti6Al4V alloy and is proximally coated with titanium plasma spray plus hydroxyapatite (HA) to promote bone attachment. The stem is distally polished and has a sagittal plane cutout to reduce distal hoop tension which has been shown to induce thigh pain [11]. Additionally, the stem has a gentle conical flare at the resection line to reduce subsidence and maintain compressive loads to the medial calcar. A lateral $\mathrm{T}$ back design enhances torsional stability reducing chances of aseptic loosening (Figures $2 \& 3$ ).

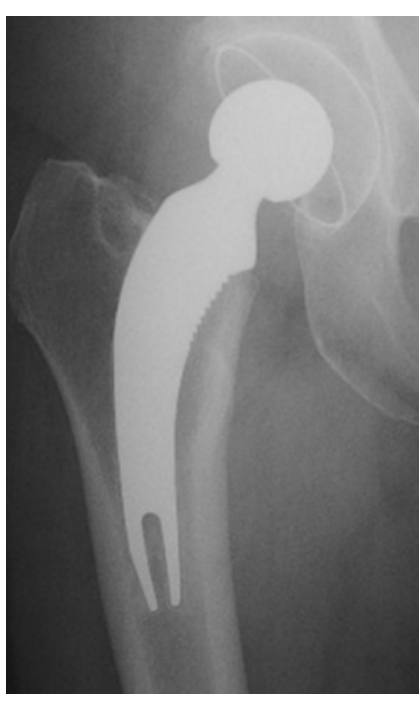

Figure 2. Post-op A/P view of TSI ${ }^{\text {TM }}$ stem and Mathys RM Pressfit Cup.

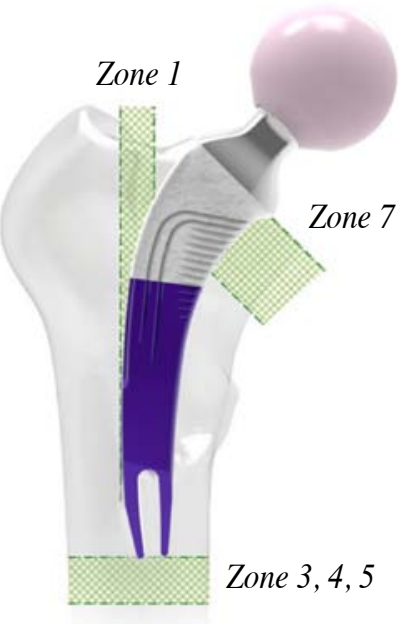

Figure 3. TSI Stem Illustration showing bone preservation in Gruen zones 1, 3, 4,5 \& 7
The simple yet novel short curved stem design reduces the need to go lateral into the trochanteric bed where you can increase damage to the musculature and cancellous bone resulting in increased blood loss. Six degrees of femoral neck anteversion is built into the TSI stem with one medial stem curve. Stem length and medial curve allow for more tissue preserving techniques for both soft and 
hard tissue without sacrificing implant stability. The internal proximal conical flair provides for a unique structure to enhance proximal compressive load transfer to the medial calcar resulting in less medial calcar resorption .

Technique Femoral Preparation. The first step is preoperative planning utilizing either plain radiographic templates or dedicated software. Both femoral neck resection and resection angle can be predetermined to ensure proper restoration of joint mechanics and stem position.

Preoperative templating is crucial to select the appropriate implant size and optimal neck shaft angle. Prosthetic templates show the implant in a true $\mathrm{A} / \mathrm{P}$ projection (approximately 20 degrees of internal rotation) while radiographs of arthritic hips may or may not represent a true A/P of the proximal femur and diaphysis because of positioning error and/or limited range of motion. If the hip is externally rotated, a position commonly seen in osteoarthrosis, the femoral neck appears shorter and more vertical $[\underline{11}, \underline{12}]$ (Figure 4).

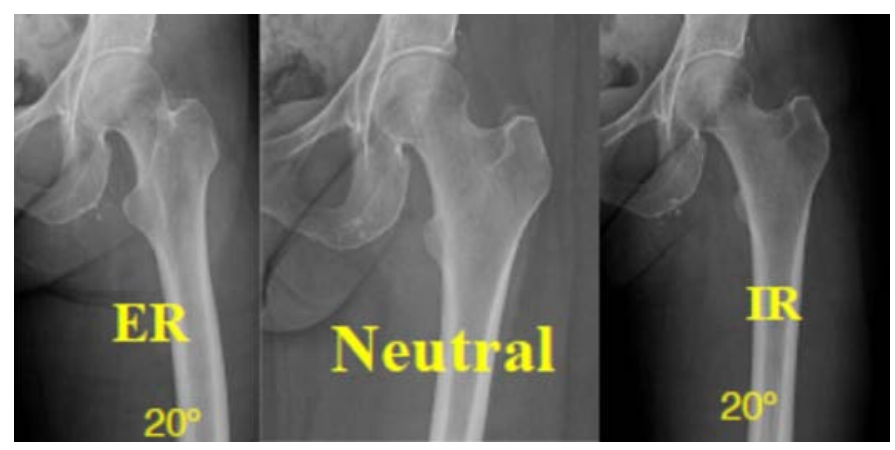

Figure 4. Radiographic views demonstrating external rotation of $20^{\circ}$, neutral and $20^{\circ}$ of internal rotation.

Lack of proper offset leads to soft tissue laxity as well as increased risk of impingement and dislocation.Templating is challenging even under the most optimal x-ray conditions since the surgeon is using two-dimensional $\mathrm{x}$-rays to assess a three-dimensional femoral head and neck. In the osteoarthritic patient the femoral head position tends to be in external rotation. Traditional radiographs taken with the foot perpendicular to the cassette underestimate offset due to the position of the femoral head with respect to the image beam. Studies have demonstrated as much as $7 \mathrm{~mm}$ can be underestimated in femoral offset in preoperative templating, especially in patients whose arthritis fixes the femur in external rotation $[\underline{11}, \underline{12}, \underline{13}]$ (Figures 5, 6).

The patient is in a decubitus lateral position with bottom and pubic support. The incision (about $8-10 \mathrm{~cm}$ ) is located on the greater trochanter's posterior part, centered at the top. The acetabular and external rotators approach is done just next to the greater trochanter and the intra-trochanteric line while dissecting the internal and external obturator muscle and the gastrocnemius muscles. Flexing the

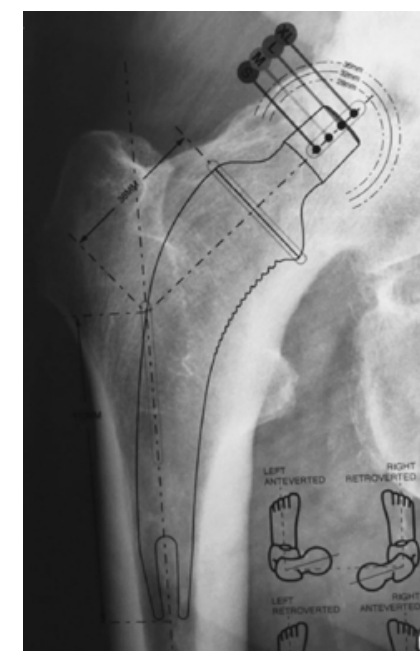

Figure 5. A/P X-ray template with femur in $20^{\circ}$ of external rotation.

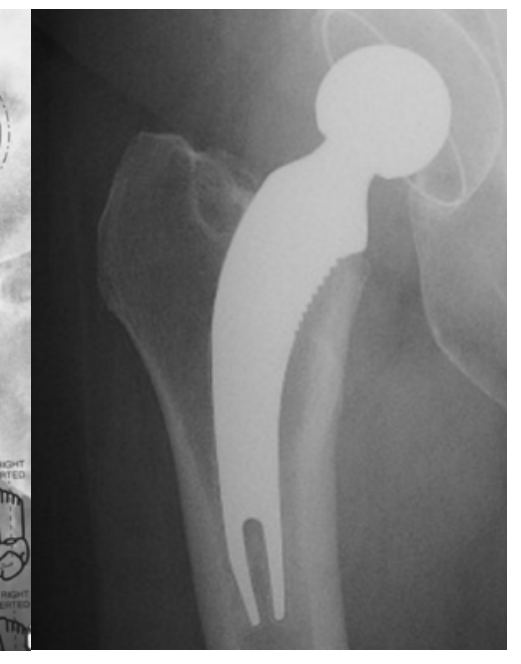

Figure 6. A/P Post-operative view with femur in $20^{\circ}$ of internal rotation.

hip and the knee, associated with an internal hip adduction rotation allows hip dislocation. The piroformis, and and the quadratus femoris muscle are preserved.

Using the postero-lateral approach to the hip, the superior one-half of the short external rotators are released from the posterior greater trochanter down to the base of the femoral neck. The capsule is preserved with transverse incisions made at the acetabular rim and the base of the femoral neck. A longitudinal capsular incision is made in between. This creates anterior and posterior capsular flaps that can be repaired at closure. Once the hip is dislocated, the femoral neck is resected 5 to $10 \mathrm{~mm}$ below the subcapital junction with a fine-toothed saw (Figure 7 ). The neck cut is based upon preoperative and intra-operative templating to restore head center of rotation. The neck sparing stem design and instrumentation is based upon following the native medial curvature of the proximal femoral neck (Figure 8).

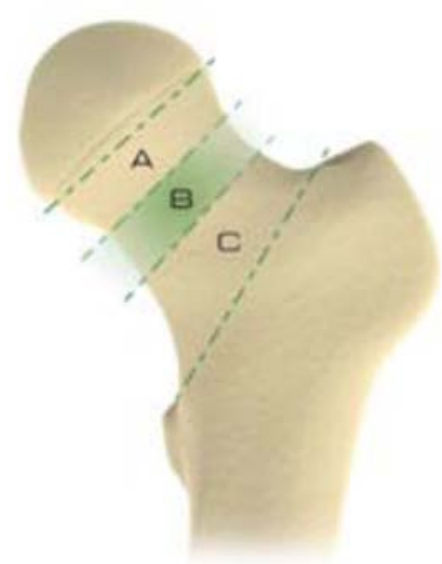

Figure 7. Illustration showing neck resection zones. Zone $B$ being $510 \mathrm{~mm}$ as recommendation.

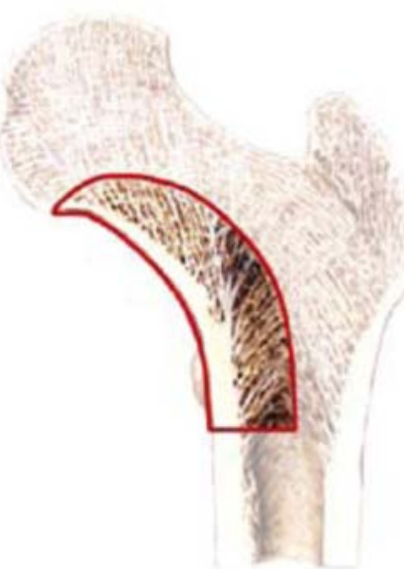

Figure 8. Illustration showing medial femoral curve. (Courtesy JISRF Archives) 
Neck resection angle is important in achieving optimal stem placement and proper biomechanical loading of compressive forces on the medial calcar. The use of a resection guide or trial stem as a cutting template is helpful ensuring the proper angle and level of neck resection (Figure 9). If the neck resection is too vertical the stem can be in valgus, if resection is too horizontal the stem can end up in varus.

Opening the femoral canal can be accomplished by a number of ways dependent on surgeon's preference. A curved curette, a curved metal sucker, a trocar drill or our preference is the curved canal finder supplied in the set of instruments (Figure 10).

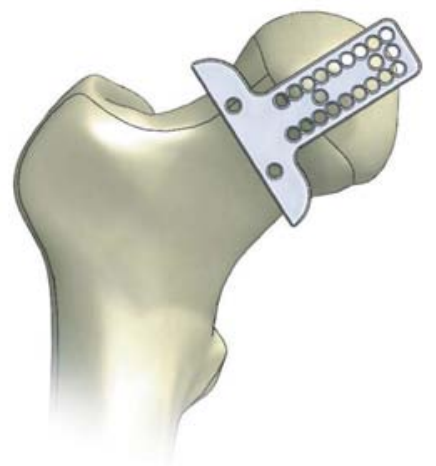

Figure 9. Align the resection guide with the femoral neck and determine the amount of femoral neck to be resected. Pin the guide into position and resect the head.

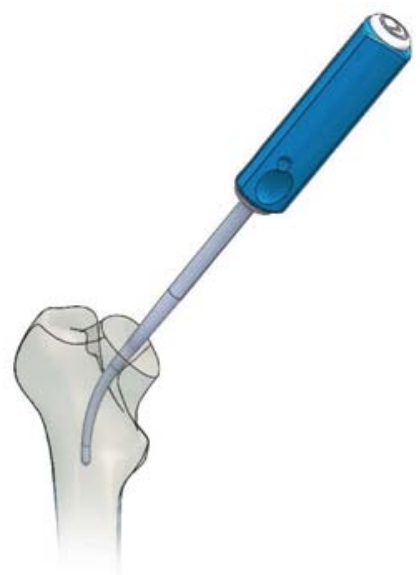

Figure 10. The curved canal finder aids in locating and following the femoral canal.

The femoral canal is then rasped with gentle force starting with the starter rasp with progression in sequence to the desired size fitting and filling the femoral neck. A canal sounder can be used to explore the distal size of the femur, and aid in determination of final stem sizing (Figures $11,12)$.

A trial reduction can be performed with the rasp in place by using the appropriate trial neck and head or by the use of the trial stem with a modular neck and head (Figures $13,14,15)$.

Trial stem can be extracted and the final definitive stem inserted with gentle force. Over impaction can result in fracturing the femoral neck (Figures 16,17).

Trial heads can be used on the final definitive stem to determine proper leg length and joint stability (Figures 18, 19).

Note: Neck-sparing stems are at increased risk for mechanical impingement, especially with retained osteophytes attached to the femoral neck. Head neck assessing for boney impingement tested at end flexion with internal rotation as well as at end extension with external rotation.

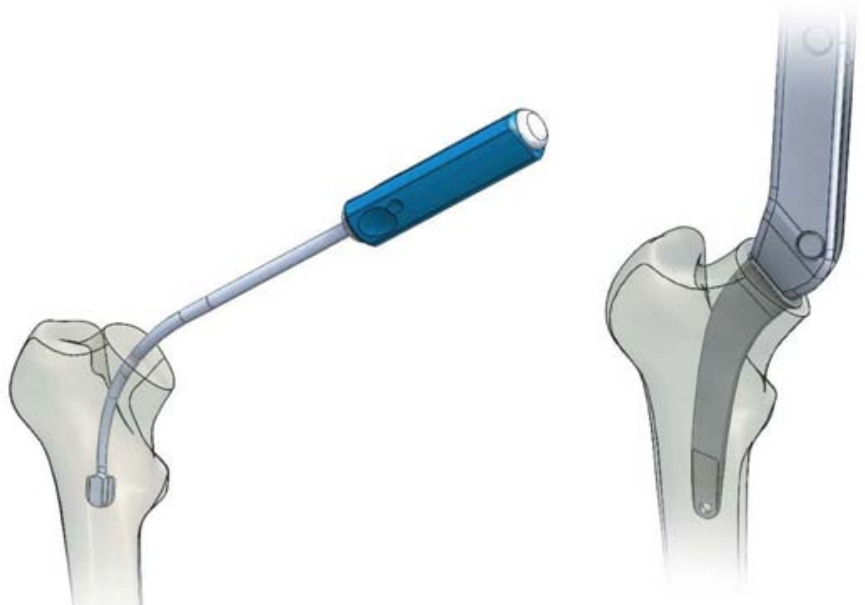

Figure 12. Rasps are

Figure 11. Illustration of completely seated when the canal sizing gauge. of the surface of the rasp is flush with the resection line.

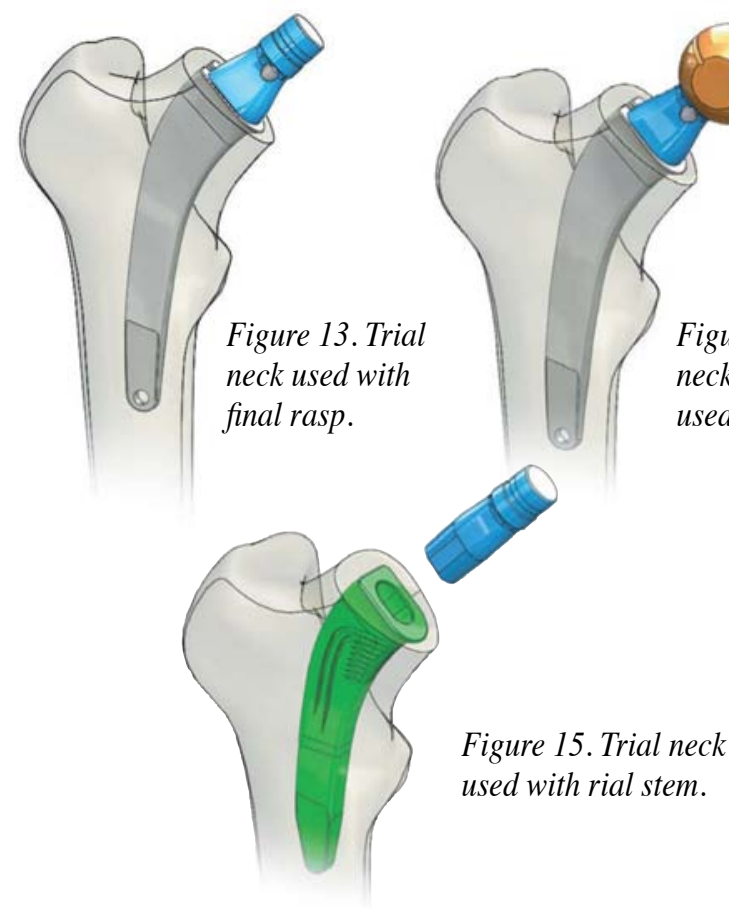

All impinging osteophytes and excess bone must be removed to maximize hip range without impingement and levering [14]. The use of head sizes of $32 \mathrm{~mm}$ or greater is recommended. Acetabuli that require a $28 \mathrm{~mm}$ head or smaller may be better treated with a dual mobility style cup design. 


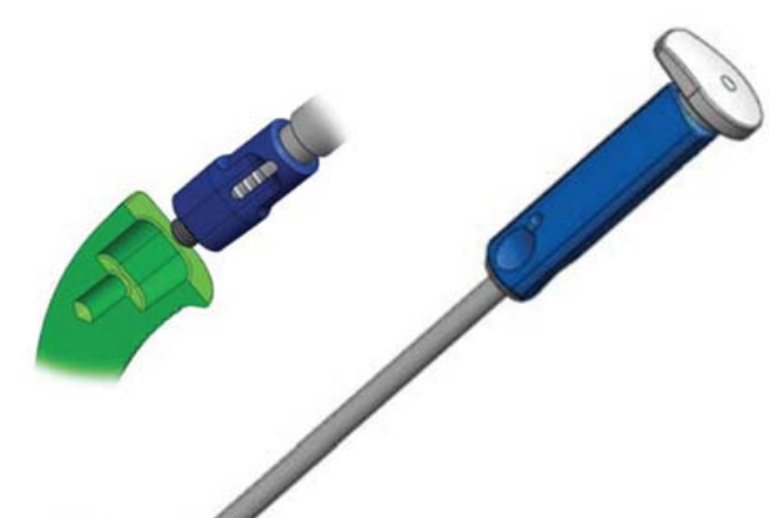

Figure 16. Trial extractor threads into the trial stem.
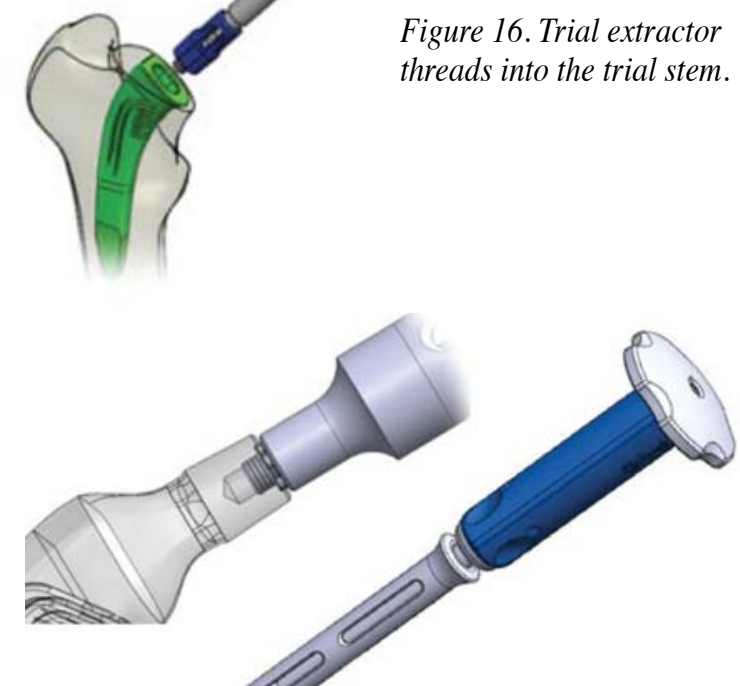

Figure 17. Stem inserter threads into the final implant.

Figure 18. Final head size is impacted onto the implanted stem.

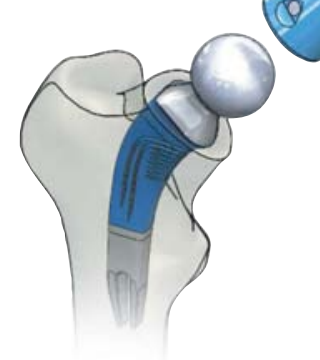

\section{Results}

There have been three femoral components explanted due to postoperative infection (Figure 20). There was one intra-operative femoral distal fracture in a Dorr type A

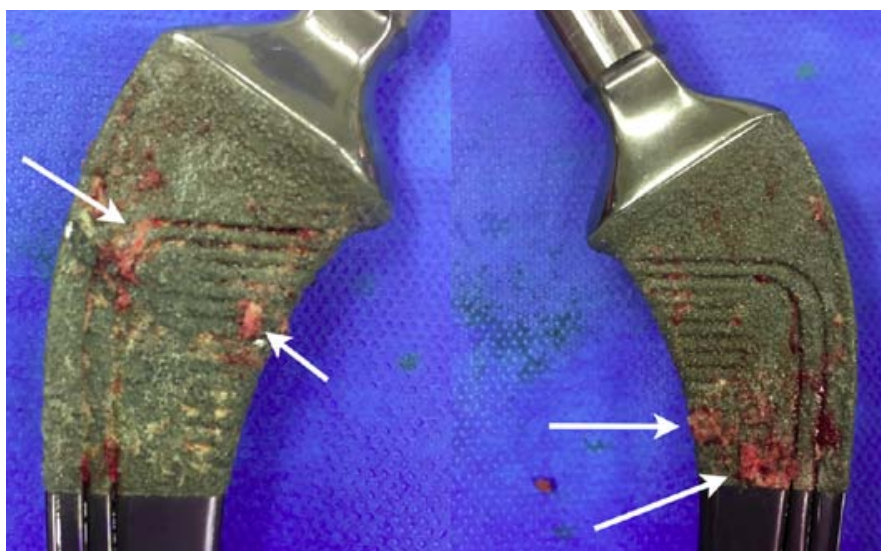

Figure 20. This stem was removed for infection at one month postoperatively was very stable with the beginning of good bone fixation through out the proximal porous coating.

bone profile during stem insertion. There one posterior dislocation; there has been two patients with thigh pain and one associated with low back pain. One patient with purely mechanical pain was very intense initially but diminished with time (1 year post-op). Now she has little discomfort and little functional limitation. At the distal lateral portion of the stem there is a lateral cortical hypertrophy without a real pedestal. This can happen if the distal lateral portion of the stem engages or wedges into the isthmus of the femoral canal. Pain reduces as the distal bone stiffens around the implant. For this reason we aim for a neutral stem position within the canal (Figures 21, 22, 23). Note the medial conical flair is slightly proud of the resection line so there is diminished proximal load transfer as seen with some mild medial bone remodeling. No leg length discrepancies greater than plus or minus $5 \mathrm{~mm}$. [14,15]

When the proximal conical flair is engaged with the medial calcar as seen in Figures 23, 24, and 25 the calcar is loaded in compressive forces and we see positive bone maintenance over the years. This is similar in radiographic results as seen and reported by van der Rijt at the European Hip Society and in 2012 Figure 26 with a similar neck sparing stem with a proximal conical flair. [16] 


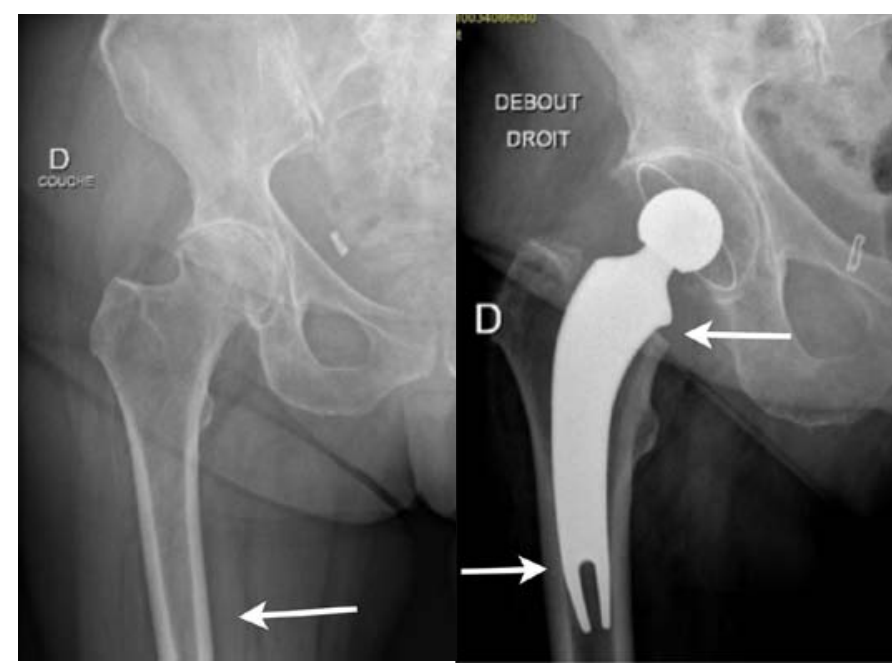

Figure 21. Patient A.

Preoperative showing a tight distal canal.
Figure 22. Patient A. Post-op demonstrating a tight distal canal fit and a slight gap at the medial conical flair.

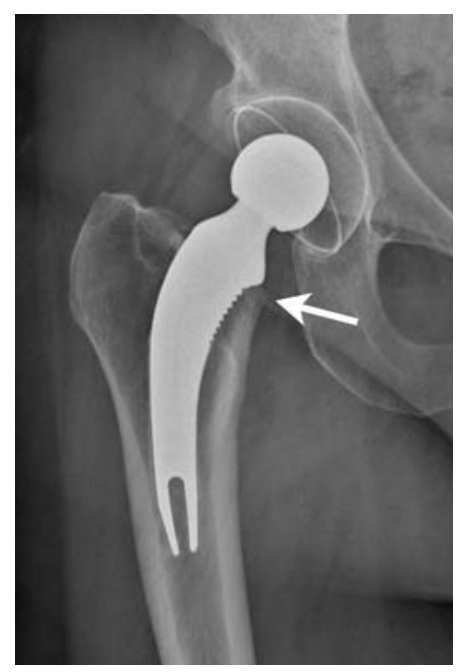

Figure 25. Patient B. December 2019.

Demonstrating good maintenance of medial calcar at 3 years postoperatively.

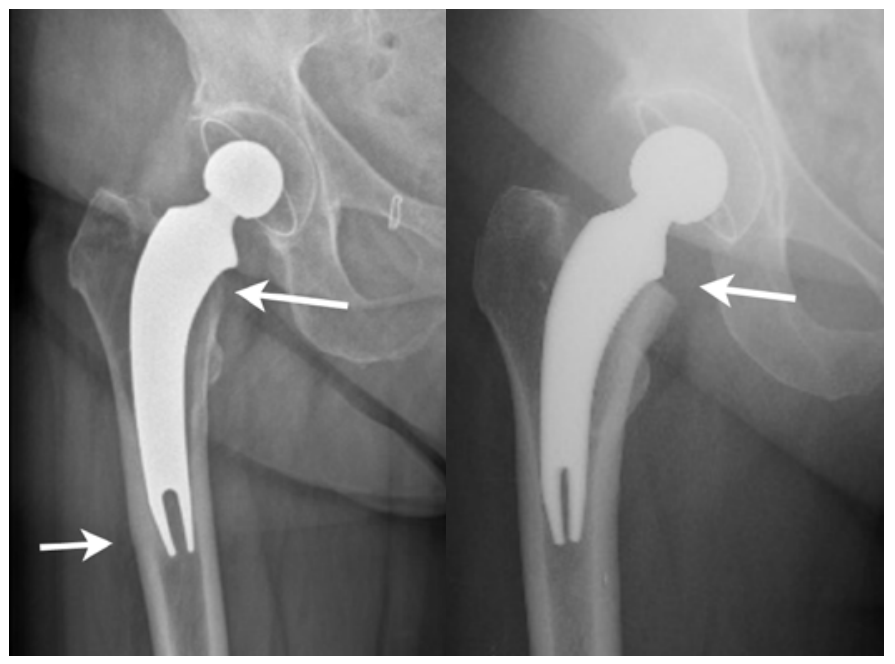

Figure 23. Patient A. One year post-op demonstrating medial calcar rounding and distal

Figure 24. Patient B. Post-op Oct. 2016. Conical Flair engaged with medial calcar.

\section{Conclusion}

This short curved tissue sparing implant has demonstrated excellent initial short-term results, with excellent implant stability, excellent medial calcar bone remodeling with one dislocated stem, no aseptic loosening two thigh pain one patient associated with low back pain, one female patient that experienced anterolateral thigh pain at six months post-operatively with diminished pain at one year and one distal intra-operative fracture in a Dorr type A bone. This has now been addressed with the use of distal sizing gauges and the use of flexible reamers to open the distal canal prior to stem insertion. Removal of the infected stems demonstrated implant stability with early bone

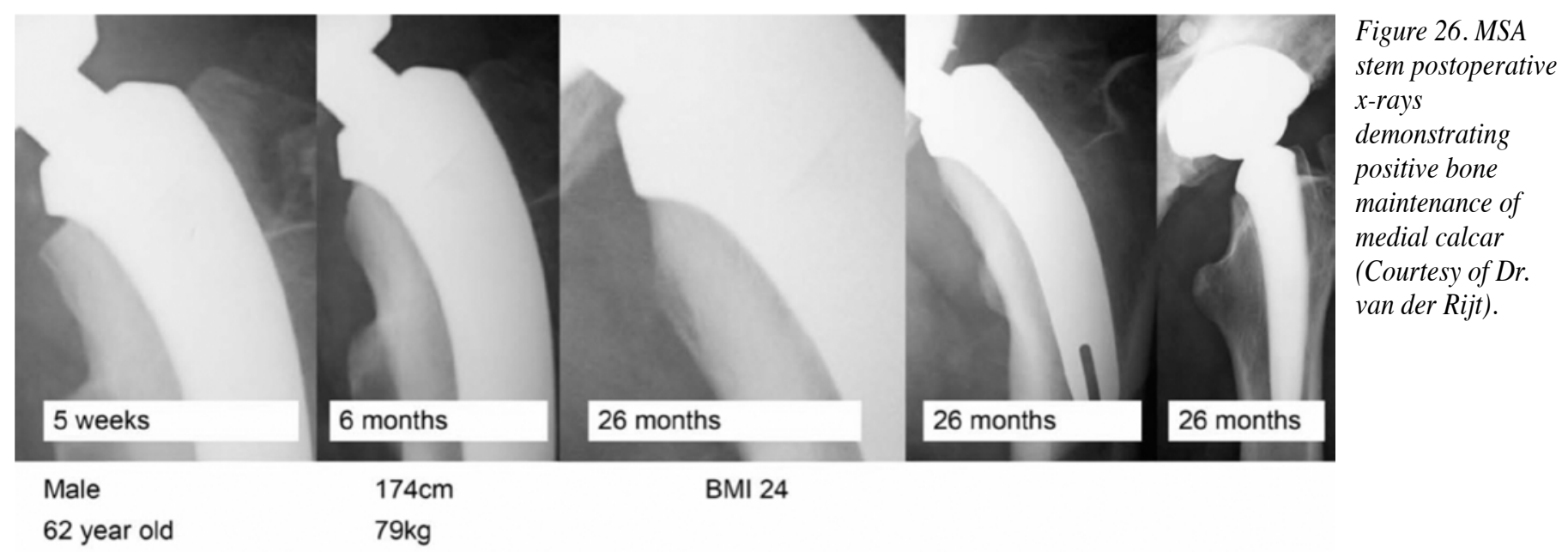


attachment in the proximal porous surface. The high neck resection allows for ease of revision and conversion implanting a new primary conventional length cementless stem design.

There is a short but definitive learning curve in fitting the implant to the femoral neck as compared to implantation of a conventional style cementless stem. The neck resection is a critical part of maintaining positive medial calcar bone remodeling. Overall the authors are optimistic and continuing advocating the use of this neck preserving style stem.

\section{References}

1. Engh CA Jr, Culpepper WJ, Engh CA. Long-term results of use of the anatomic medullary locking prosthesis in total hip arthroplasty. J Bone Joint Surg Am. 1997;79:177-184

2. Polkowski GG, Callaghan JJ, Mont MA, Closhisy JC. Total Hip arthroplasty in the very young patient. J Am Acad Orthop Surg. 2012 Aug;20(8):487-97. doi: 10.5435/JAAOS-20-08-487.

3. Girard J, Glorion C, Bonnomet F, et al. Risk factors for revision of hip arthroplasties in patients younger than 30 years. Clin Orthop Relat Res. 2011;469(4):11411147

4. Barrack R,. The Case for Hip Resurfacing: A Bigger Picture. Current Concepts in Joint Replacement Meeting. December 2010.

5. Amstutz HC. Hip Resurfacing: A 40-year Perspective. HSS J. 2012 Oct;8(3):27582. doi: 10.1007/s11420-012-9293-9. Epub 2012 Sep 14.

6. Wong JM, Liu YL, de Steiger R. What is the Rerevision Rate After Revising Hip Resurfacing Arthroplasty? Analysis From the AOANJRR. Clin Orthop Relat Res. 2015 Nov;473(11):3458-64. doi: 10.1007/s11999-015-4215-z.

7. Clarke I, Lazennec J. Margin-of-safety Algorithm Used with EOS Imaging to Interpret MHRA Warning for 46-48mm MOM Arthroplasty. https://doi. org/10.15438/rr.5.3.115

8. McTighe T, Woodgate I, Turnbull A, et al. A New Approach to Neck-Sparing THA Stem. March 2008 DOI: 10.13140/RG.2.1.1799.5367, Conference: AAOS At: San Francisco Volume: Poster Exhibit 32

9. McTighe T, Brazil D, Keggi JM, Keppler L, McPherson EJ. "Short-stem Designs for Total Hip Arthroplasty: Neck Stabilized Femoral Components" In book: The Adult Hip "Hip Arthroplasty Surgery" Third Edition, Chapter 64, Publisher: Wolters Kluwer, Editors: John J. Callaghan, Aaron G. Rosenberg, Harry E. Rubash, John C. Clohisy, Paul E. Beaule, Craig J. Della Valle, pp.823-849

10. McTighe T, Stulberg SD, Keppler L, Keggi J, et al. Total Hip Stem Classification System. https://doi.org/10.15438/rr.v4i2.70

11. Schutte D, Conrad J, Romero N, McTighe T. http://www.jisrf.org/pdfs/predictingtotal-hip-arthroplasty.pdf ICJR Poster 59 April 27-29, 2012 Coronado, CA

12. Lindgren JU, Rysavy J. Restoration of femoral offset during hip replacement. A radiographic cadaver study. Acta Orthop Scand. 1992;63(4):407-410.https://www. ncbi.nlm.nih.gov/pubmed/1529690
13. Sakai, T, Sugano, N, Ohzono K, Nishii T, Haraguchi K, Yoshikawa H. Femoral anteversion, femoral offset, and abductor lever arm after total hip arthroplasty using a modular femoral neck system. J Orthop Sci. 2002;7(1):62-7. DOI: 10.1007/ $\underline{\mathrm{s} 007760200010}$

14. McPherson E, Vaughn B, Keppler L, Brazil D, McTighe T. The Incidence of Dislocation Utilizing a Neck Sparing Stem in Primary THA in Community Based Practices with the Posterior Approach. https://doi.org/10.15438/rr.5.2.106

15. McTighe T, Brazil D, Keggi J, Keppler L, McPherson E. Short-stem Designs for Total Hip Arthroplasty: Neck Stabilized Femoral Components. https://www.researchgate.net/publication/301689235 Short-stem Designs for Total Hip Arthroplasty Neck Stabilized Femoral Components

16. Van der Rijt A, Van der Rijt R, Solaiman R. Early experience with MSA $^{\mathrm{TM}}$ neck sparing stem via anterolateral approach. Oral Paper at European Hip Society 10th Congress; September 2012; Milano, Italy.

\section{SUBMISSION HISTORY}

Submitted: January 2, 2019

Reviewed: March 24, 2019

Accepted: March 26, 2019

Published: March 31, 2019

\section{AUTHOR AFFILIATIONS}

1 Guillaume Venet, MD; Antoine Tesson, MD; Francois Le Cour Grandmaison, MD; Nicolas Fraquet, MD

Service de Chirurgie Orthopédique et Traumatologique, CHD VENDEE, 85925 La Roche Sur Yon Cedex, FR

2 Declan Brazil, PhD

Signature Orthopaedics, 7 Sirius Rd Lane Cove West NSW 2066 AU

3 Timothy McTighe, Dr HS (hc) Joint Implant Surgery \& Research Foundation, 46 Chagrin Shopping Plaza, \#117, Chagrin Falls, OH 44022 US

(Direct inquires to Guillaume Venet, guillaume.venet@chd-vendee.fr)

\section{AUTHOR DISCLOSURES}

Guillaume Venet, Declan Brazil and Timothy McTighe declare Either family, institution I am associated with, or I have received benefits or funds either directly or indirectly regarding this article.

Drs. Tesson, Le Cour Grandmaison and Fraquet declare that there are no disclosures regarding the publication of this paper.

\section{COPYRIGHT \& OPEN ACCESS}

(C) 2019 Venet, Tesson, Le Cour Grandmaison, Fraquet, Brazil, McTighe. All rights reserved.

Authors retain copyright and grant the journal right of first publication with the work. Reconstructive Review is an open access publication and follows the Creative Commons Attribution-NonCommercial CC BY-NC. This license allows anyone to download works, build upon the material, and share them with others for non-commercial purposes as long as they credit the senior author, Reconstructive Review, and the Joint Implant Surgery \& Research Foundation (JISRF). An example credit would be: "Courtesy of (senior author's name), Reconstructive Review, JISRF, Chagrin Falls, Ohio". 


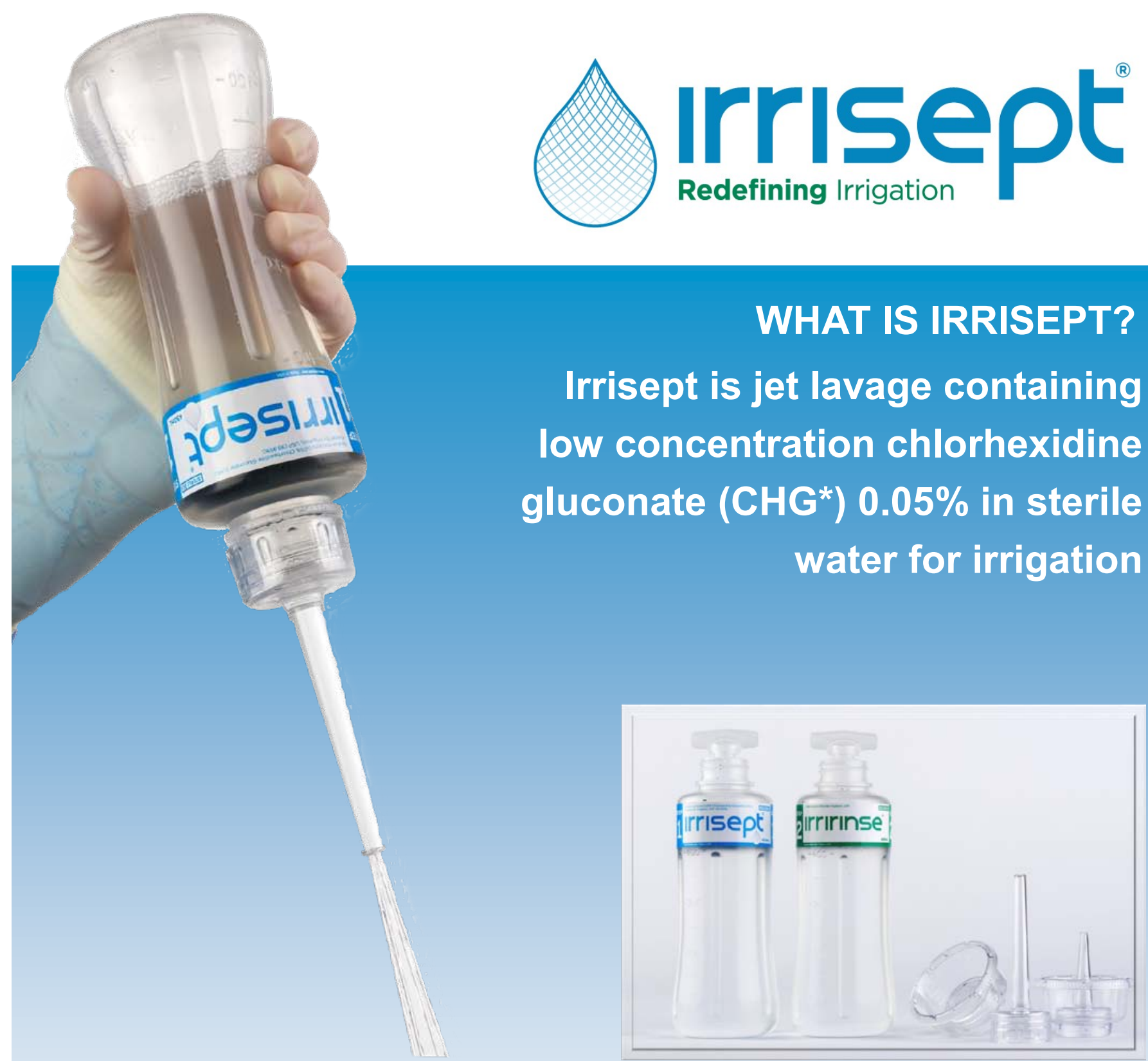

Irrisept is sterile packaged, contents include:

\section{HOW IRRISEPT WORKS}

Irrisept's bottle design allows users to control the pressure of the solution through manual bottle compression.

The mechanical action of Irrisept helps remove bacteria, particulate and debris in wounds without harming underlying tissues. 